\title{
The Impact of Pornography on Adolescent Males' Sexual Behaviour in the Eastern Cape, South Africa. A Qualitative Study
}

\author{
J.G. Kheswa \\ Department of Psychology, University of Fort Hare, Private Bag X1314, Alice, 5700, South Africa. \\ Email:jkheswa@ufh.ac.za \\ M. Notole \\ Department of Psychology, University of Fort Hare, Private Bag X1314, Alice, 5700, South Africa. \\ Email: 201004723@ufh.ac.za
}

\section{Doi:10.5901/mjss.2014.v5n20p2831}

\section{Abstract}

A disproportionate number of adolescent males view pornography despite the negative effects it has on their psychological, emotional and cognitive development. In many black communities in South Africa, as a result of conformity to peer influence, substance abuse and lack of parental supervision, research indicates that adolescent males tend to access pornography and end up raping women. This empirical study employed qualitative approach to gather information from ten male participants, aged 14 -18, from one secondary school in the Eastern Cape. Ethics were adhered to as the human dignity of the participants was respected. None of the participants withdrew from the focus group. Considering the sensitivity of the topic, the discussion took place in one of the classrooms and not even their educators could identify the participants. The findings revealed that male youth who watch pornography, drink alcohol and gang-rape, which increase their risk of contracting HIVIAIDS. Furthermore, this group of adolescent males reported that their aggressive behaviour is perpetuated by culture. Recommendations are that parents should be involved in discussions of sexual matters with youth.

Keywords: pornography, alcohol abuse, adolescent males, peer- pressure, aggression,

\section{Introduction}

Internet use around the world gains momentum daily. $93 \%$ of adolescents in the United States have an access to internet (Lenhart, Purcell, Smith \& Zickhur, 2010), 95 \% in Canada, and 98\% in Israel ( Lawsky, 2008). Along with this rise in internet usage, numerous sexual assaults by adolescent males have been reported (Kraus \& Li, 2006; Wolak \& Finkelhor 2013). Globally, a body of research indicates that majority of adolescent males who struggle with compulsive internet use and compulsive behaviour related to internet pornography and cybersex (Delmonico \& Griffin, 2008; Owens, Behun, Manning \& Reid, 2012) have the propensity to express their sexual prowess at an early age with multiple sexual partners as compared to male youth that is not exposed to the internet use (Brown, Keller \& Stern, 2009). Concerns are raised that the more adolescents access pornography, the more they become desensitized (Eberstadt \& Layden, 2010). Desensitization refers to the behavioural response in which an adolescent male feels relaxed towards a phobia or in situation he dreads most (Comer, 2013).

South Africa is not exceptional to the dilemma experienced by adolescent males from other countries. Louw and Winter (2011) found that 64\% of children between 13 and 17 years had been exposed to pornographic material through internet. Male youth cite reasons such as curiosity, relief from boredom or acquisition of sexual skills, and experience of sexual arousal for viewing pornography (Bale, 2011; Cowell \& Smith, 2009). Pornography viewing precipitates sexual coercion and aggression among males since in films and movies, females are being objectified as victims of sexual violence (Bonino, Ciairano, Rabaglietti \& Cattelino, 2006). Flood (2009) describes pornography as body-punishing sex in which females are demeaned and debased. Research findings in the study which investigated the impact of alcohol consumption on the sexual behaviour of adolescent males in the Eastern Cape, South Africa, Takatshana (2013), found that the extensive viewing of sexual violence and rape on television or movies had an adverse effect on the sexual behaviour of youth. Majority of the participants reported pornography and alcohol use to be precursors of aggressive sexual behaviour. Aggressive behaviour contributes to rape perpetration. George (2001) mentions that in most cases high sexual violence is perpetrated in educational settings. Döring (2014) further states that almost high school females 
had encountered forced sexual intercourse in school. Adolescent males become aggressive due to early pornography exposure which may lead to rape. Aggressive behaviour in boys develops in childhood as a chronic behaviour that becomes a risk factor for antisocial behaviour in adult life.

Drawing from Albert Bandura's social learning theory, adolescents who are exposed to violent messages broadcast on radio and television, printed in magazines, distributed on the Internet and presented in video games are likely to display aggressive behaviour (Pastorino \& Doyle-Portillo, 2009). Because of immature cognitive development, adolescent males tend practice what they witness from the sexually explicit material and sexually coerce their partners (Elliot \& Beach, 2009). According to Omar (2012), pornographic images leave deeper impression on the brain of adolescents in comparison of to that of adults. Adolescent's brain is not fully developed in frontal cortices to exert cognitive control required to suppress sexual urges and behaviour elicited by pornographic material (Casey \& Jones, 2010).

\section{Religiosity}

According to Brandy, Brian, Magarel Randal and Sharon (2004) religion has been theorized to influence individual adolescent's sexual behaviour directly and indirectly through mechanism of social support and social control interacting at multiple levels of the adolescent's social context. Families with higher levels of religiosity are likely to have obedient children than other teenagers from different families to avoid early sexual behaviour and the associated risks of pregnancy and STDs. However, adolescent males whose religiosity is not solid, have the tendency to exchange sexualized pictures that are not self-produced (i.e. pornographic images from the internet). In most cases they would send their victims semi- nude pictures or videos which depict sexual activities (e.g. vaginal penetration or masturbation) via their cell-phones (Döring, 2014). The theoretical explanation of these strategies is viewed as cyberbullying. According to Chisholm and Day (2013), cyberbullying is intentional act of provoking another person through sending of unwelcoming messages or pictures. In most cases, cyberbullying could be in the form of stalking or threatening an individual when failing to comply.

Adolescent males who prey on their female victims, seduce them by introducing movies with high sexual content (Wolak \& Finkelhor, 2013). According to Poulsen, Busby and Galovan (2013), such youth do not have strong ties to religion and majority of them drink alcohol and use drugs. In communities which embrace culture, their male youth end up in jail as a result of statutory rape or acquaintance rape after they had a chance to meet their victims (Jewkes, 2012). Supporting the notion above is Jeriphannos, Kudakwashe and Phinias (2004) who found that in African cultures if a woman or a girl says "no" to sex, a man tends to ignore the emotional well-being of the females and do the opposite. Because of the cultural influences, boys who were socialized from an early age into traditional patriarchal notions of masculinity, which promote and legitimize unequal gendered power relations, had been physically abusing their female partners as opposed to the non-socialised youth (Jewkes \& Morrell,2012; Petersen, Bhana \& McKay, 2005).

\section{Peers and Pornography}

According to Kirby (2001), adolescents ranging from 13 to18 years old are likely reported to get information about sexual health issues from their peers whereas Holborn and Eddy (2011) found that pressure to engage in sex increases during middle adolescence especially if the adolescent males lack father figures or perceive their fathers as losers. They begin to experiment sexual intercourse under the influence from their peers and these influences are associated with a broad range of high-risk behaviour mainly unprotected sexual intercourse. Findings from the World Health Organisation (2007) revealed that about 11 million sexual transmitted infections are recorded each year in South Africa and half of the infected are between 15-24-year-olds and mostly residing in rural areas. According to Eaton, Flisher and Aaro (2003) this high incidence of sexual transmitted infections indicate that adolescent males could also be involved in sexual activities due to peer influence, pornography and lack of parental guidance.

Reid, Carpenter, and Fong (2011) highlight several parallels between pornography consumption and maladaptive behaviours. For example, Braun- Courville and Rojas' (2009) in their qualitative study found that adolescent males indicated that their exposure to explicit sex material put their lives at risk of contracting sexually transmitted infections (STIS) including HIVIAIDS because they engaged in unsafe sexual practices as a result of impulsivity, conformity and influence of alcohol. Louw and Louw (2007) state that the negative influences most adolescent males receive from their peers with regard to their sexual behaviour is the notion that there is nothing wrong with sexual act or activities. In addition, Greenberger, Chen, Beam, Whang and Dong (2000) found that these male adolescents outweigh the costs of sexual involvement, view sex as rewarding and as a way to fit in with their peers. Furthermore, Pastorino and Doyle- 
Portillo (2009) identify that peer influence usually occurs when adolescent males misconduct in their leisure time in which in most cases they engage in risky sexual behaviour which mostly occurs especially in groups. Petersen, Bhana and McKay (2008) noted that the pressure reinforces the individual to exert on their members to conform to certain norms for instances drugs and sexual act behaviour.

\section{Effects of Pornography}

According to Omar (2012), adolescent males who view pornography tend to exhibit high level of parental separation, live in sexualized environments which are characterized by substance abuse and have history of childhood traumas.

Pornography viewing hinders social development with respect to forming intimate relationships with family, educators and society (Mesch, 2009). As a result of emotional aloofness and detachment, majority of adolescents who are addicted to pornography tend to display lack of empathy, low level of self-esteem and self- efficacy (Elliot \& Beach, 2009). According Ryckman (2008), self-efficacy is an individual's beliefs about his/her ability to perform a particular behaviour in a given situation, mediating the relation, knowledge and skills related to performing a behaviour and his or her actual performance of the behaviour. Furthermore, sexual self-efficacy can be described as an individual's attitude about her or his own sexual ability, knowledge, and skills. Male adolescents who spend their leisure time on pornography watching tend to have a lower level of sexual self-efficacy than non-exposed adolescents (de Bruijn, Burrie \& van Wel, 2006). According to Ryckman (2008), positive sexual self-efficacy (resistive self- efficacy) in adolescent is associated with lower sexual risk taking. On the other hand, adolescent associated with higher sexual risk taking and maladaptive behaviour owing to pornography viewing, display permissive attitude towards condom use, perform poorly academically and likely to drop school prematurely (Best \& Fortenburry, 2013).

Having previously mentioned that pornography leads to aggressive behaviour, research indicates that adolescent males due to external locus of control, find themselves exerting physical power and threats to their sexual partners, siblings or acquaintances to have their sexual desires met. According to Jewkes and Morrell (2012), high prevalence of rape is perpetrated by peers on the adolescent male to prove his hegemonic masculinity. In South Africa, rape is underreported as most females fear for reprisal. The danger is that in most cases, victims of statutory rape are left physically injured and experience depressive symptoms (Jewkes, 2012). Statutory rape is a general term to describe an offense that takes place when an individual regardless of age has consensual sexual relations with an individual younger than 18 years of age (Flores, 2005). Hence, Kheswa, Dayi and Gqumani (2014) and Unni (2010) assert that it is important to teach male youth that irrespective that there may be no threats or coercion, engaging in sexual activities with a minor is against the law. In the Children's Bill that was released in 2003 by the Minister of Social Development, Mr. Zola Skweyiya made it clear that children are entitled to protection from maltreatment, abuse, discrimination, exploitation and any other physical and moral harm. However, Jewkes, Sikweyiya, Morrell and Dunkle (2011) in the study conducted in Eastern Cape and KwaZulu-Natal in order to understand statutory rape perpetration, established that $27 \%$ of adolescent males agreed that they had forced a minor to have sex with them against their will.

\section{Theoretical Framework}

The theoretical framework not only positions the research in which the researcher is working but provides and orientation to the study (Henning, Van Rensberg \& Smit, 2004). In this research study, various theories related to pornography and sexual behaviour were used to verify the findings of the empirical investigation. Drawing from excitation transfer theory developed by Schachter and Singer (1962), an adolescent male who was previously angered is most likely to manifest higher levels of aggression after pornography exposure, since the external stimulus (e.g. media) has triggered their emotional state. On the other hand, Albert Bandura's social learning theory explains that the behaviour in terms of interaction between cognitive, behavioural and environmental determinants. The emphasis is on the importance of observing and modelling the behaviour, attitudes and emotional reactions of others (Louw \& Louw, 2007). For instance, seven adolescent males gang-raped a mentally-retarded girl from Soweto, filmed the sexual activity on their cell phones and circulated the footage via social media (Holtzhausen, 2012). Various scholars assert that an alarming proportion of South African parents refrain from educating, disciplining and policing their children's cell phones, despite knowing that there is strong association between pornography consumption and aggression (Brand, Laier, Pawlikowski, Schachle, Scholer \& Altistottle- Gleisch, 2011; Le Roux, 2010; Posel, 2008).

For instance, one South African study by Holborn and Eddy (2011), found out that broken families break the parent-adolescent interactions because the father plays a reliable role in the male adolescent's sexual behaviour development. Due to lack of the father being there the male adolescent's relationships with peers and sexual partners 
become weak, tainted by lack of support from other figures in the family. According to Zenzile (2008) adolescents who experience poor housing conditions and guidance from their parents tend to hang around on the street and engage themselves in rape activities. According to Jemmott, Heerlen, Ngwane, Hewitt, Jemmott, Shell and Leary (2007), rape of woman or girls is prevalent in many societies, hence the number of children awaiting trial increased by $53 \%$ to 2197 in December 2003, and the adolescent males in prison increases. Against this background, this research attempted to answer the following research questions:

- What fuels adolescent males to engage in pornography viewing?

- How has pornography contributed to the sexual behaviour of adolescent males?

- Are the adolescent males knowledgeable about criminal /legal implications of committing statutory rape?

\section{Research Method}

The researchers used the qualitative research design for it is explorative, descriptive and inductive in its approach. Qualitative research allows data to be collected in the form of written or spoken language and analyzed by identifying and categorizing themes (de Vos, Strydom, Fouche \& Delport, 2005). As researchers, we selected issues in depth, openness and in details to identify and attempt to understand the categories of information that will merge from the data.

\subsection{Research Population and Sample}

Given the aim of the study, the target population was the adolescent males, attending Secondary school in Eastern Cape Province, South Africa. The sampling technique that the researchers used was purposive sampling because in purposive sampling the researchers select only those individuals that yield the most information about the topic under investigation as suggested by Leedy and Ormrod (2005). The sample comprised ten African male youth, whose age ranged from 14 to 18 years.

\subsection{Instruments}

Focus- group interview was employed as this method has multiple advantages for the study. It provides a comfortable environment, which facilitates disclosure, encourages elaboration and allows for adolescent males an opportunity to recall the events where they demonstrated aggressive sexual behavior as a result of pornography viewing. Unlike in a quantitative research, where participants respond to the closed-ended questionnaire, in qualitative research, the researchers become actively involved for clarity seeking questions while the conversation is driven by the participants. This frees the discussion from existing preconceptions and allows the researchers to engage with unforeseen topics that may arise during the course of the discussion (Leedy \& Ormrod, 2005).

\subsection{Materials}

A semi- structured interview schedule was developed to guide the focus group discussion. The schedule consisted of a series of core questions to ensure a degree of comparability between resultant transcripts. Core questions were derived from the conceptual framework of this study to ask the participants to comment upon the various factors leading adolescent males to view pornography and its effects on sexual behaviour. The issues discussed included: reasons for intimate partner violence, the relationship between substance abuse and pornography, and the recommendations to alleviate sexual aggression associated with pornography.

\section{Trustworthiness}

In establishing the "truth value" of the research study, four alternative constructs by Lincoln and Guba (1985) were followed, namely; credibility, transferability, dependability and confirmability .

- Credibility refers to how accurately the data reflect reality (Maree, 2010). In this research study, as suggested by Creswell (2008) the researchers became involved during the focus group when the participants responded to the open-ended questionnaires in face to face interview to ensure that finding are credible.

- Generalizability: According to Maree (2010), generalizability is the extent to which generalization can be made from findings to a population. As six participants as the sample for this study were used, the sample 
shared the same characteristics (e.g. culture, race and language) and the sample's empirical findings could be made broader inferences.

- Confirmability: It is the degree to which others can confirm the results (Babbie, 2008). In this research study, the researchers relied on details of the participants' response which were later coded using axial coding from grounded theory approach.

- Dependability: Dependability reflects how truthful the researcher is. It is the collection and presentation of data (Babbie, 2008). In this study, the researchers asked the questions which are embodied in the theory of abortion.

\section{Ethical Consideration}

Ethical principles were complied with as they served to safeguard the dignity, rights, safety and well-being of all the participants in the research study. The researchers ensured that the ethical principles met the national and international standards governing research of this nature with human participants (Leedy \& Ormrod, 2005). The Research Committee of the Faculty of Social Science and Humanities endorsed the study and informed consent was obtained from each participant prior to conducting the focus group (by signing the consent form) after the school principal had granted the researchers permission. By informed consent, Maree (2010) states that the participants must be told prior to the research what the nature thereof will be and what the procedure will entail and furthermore they may cease participation in the study at any time without penalty as the study is voluntary. The focus group was conducted in one class at school, in August 2013, with chairs placed in a circle in the middle of the room. A tape-recording device was placed on a small table in the middle of the circle to ensure optimal recording of the focus group interview. It was explained to the group that there would be recorded, their human rights respected and anonymity reassured. Since the study under research was sensitive, the researchers ensured that the participants do not experience psychological discomfort. The environment was quiet and none of their friends or educators interrupted during the process of interviews. All participants were assured that data collected will be treated with confidentiality and that it will be only be used for the purpose of this study and when published their names will never be revealed. During the interview, participants were not even asked to mention their names.

\section{Analysis}

Before the interview commenced, the researchers started by building a rapport to make the participants to be at ease. Though the discussion lasted approximately 40-50 minutes, the participants were encouraged to express themselves in their mother- tongue (i.e. isiXhosa). The focus group interviews were transcribed from the tape recordings into both electronic and printed form. Each transcript was read several times before beginning the analysis, as suggested by Creswell (2008). To identify themes of this study, the researcher used the following steps as suggested by de Vos, Strydom, Fouche and Delport (2011), open coding, axial coding and selective coding. In open coding the data was divided into segments and then scrutinized for commonalities that reflected categories or themes. After the data was categorized it was further examined for properties, specific attributes or subcategories that characterized each category. Secondly, axial coding was done. Axial coding entails making interconnections among the categories and subcategories (Leedy \& Ormrod, 2005).

\section{Discussion of Research Findings}

The analysis resulted in the development of six key themes:

\subsection{Modelling of aggressive sexual behaviour}

Most participants reported that mass media plays a major role in influencing them to sexually harass girls, specifically television because that is where they watch movies (romantic movies). Dramas like Yizo-Yizo or Intersexion on SABC 1 portrays men as capable of love, rape and violence With regards to the question "How has mass media contributed to your behaviour in sexually offending women or girls"?

The participants responded as follows:

"After watching yizo-yizo on TV and smoking or drinking alcohol I used to develop some sexual feelings and fantasize 
about being involved in raping a woman with my friends"

"Mass media has an impact because they see people kissing in Generations, watch pornography and tend to imitate that to test and prove themselves as men"

"We as males are copying on what we see in movies and music videos then assume that girls are supposed to be like those we see on Television and acting like them also like in pornography, hence we force sex upon them"

This is actually in line with the fact that television as the type of mass media plays a major role to the sexually offence of girls. In study by Bahr, Hoffmann and Yang (2005), it was established that learning takes place during interaction with friends as well as through mass media. Similarly, according to the study based on Yizo-Yizo, Clive (2004) states that Yizo-Yizo covers topics such as violence, sexual harassment and drug abuse, so this is evident that adolescent males who sexually offend girls learn from those dramas broadcasted on television and mimic what they see.

\title{
10.2 Gang-rape and drugs
}

Majority of the respondents agreed that pornography has a powerful effect in the sense that they had learnt to sexually coerce women. With regard to the question: "How has pornography influenced you and your peers"?, the male participants cited the following:

\begin{abstract}
"When it is weekend, we go to the tavern and one of our friends would propose a girl and buy her alcohol. When she is still drinking, our friend would pour her a drug inside her bottle to get drunk. From there it becomes easier to rotate her and implement different sexual styles we have learnt from porn"

"My friend and I normally invite a girl to my room when parents are already asleep in their house or when not around. The girl finds us having organised beers and her favourite wines (e.g. savannah or Smirnoff spin). After an hour or two, we talk about sex and ask her if she has ever watched porn, and if she says no, we let her watch it. From there we know we touch, kiss and undress her"
\end{abstract}

This finding is in line with what Jewkes, Sikweyiya, Morrell and Dunkle (2011) found to be common in taverns. In their quantitative study research, a total of $8.9 \%$ of adolescent males reported to have gang-raped a woman without her consent and she was too drunk to stop them. In another article from the newspaper, Mail and Guardian by Malan (2013) found that adolescent males from Polokwane, Limpopo Province, South Africa, accepted that on a weekend they had rotated a girl while they were in a tavern. This means that most of these incidences happen in places where one drinks alcohol in taverns or private parties where girls are being manipulated to drink too much so that it will be easy to take advantage of them. Because drugs are easily accessible in many communities, the implication is that girls may not remember how they got raped, became pregnant or infected with sexually transmitted infections due to blackout amnesia. Similarly, in a study carried out in Sweden to investigate the effects of pornographic viewing, Seto, Hermann, Kjellgren, Priebe, Svedin and Långström (2014), found that adolescent males who gang-raped females agreed to have watched pornography with friends and enjoyed casual sex with multiple partners.

\subsection{Lack of communication and trust amongst the family}

The researchers found out that, the adolescent male who indulge themselves in rape do not have good communication with their family members. This theme emerged on the question that says "Describe your relationship with your family members with respect to valuing sexual relationships (e.g. trust, love detachment)"

Participant replied that:

\footnotetext{
" the relationship with family is not good, I stay with my mother and sibling, so she does not have time for me so that is why I behave the way if do and also at home they do not trust me they think that I might rape my siblings"

"I live with my grandparents, my father and cousins and I am not close with my family members and we do not communicate about sexual related issues"

"No I do not communicate with my family about sex issues or sexual relationship issues

"I do not communicate with my family about sex relationship, I feel ashamed and tense".
}

From the responses of the participants it is clear that adolescent males who sexually offend girls come from uninvolved parents. Uninvolved parents are that show minimum interaction and affection towards their children and they are unaware of the adolescent's needs and become uninvolved to the point of being neglectful which in return exposes children into bad behaviour because they did not get proper supervision from their parents (Takatshana (2013). 
According to Stevens and Cloete (2010) neglect refers to a condition in which a child may be deprived of what is necessary to his or her existence and what is his or her right by virtue of that existence. As a result, such children demonstrate a higher risk of diagnosis later in life of anti-social personality disorder.

\subsection{STIs and HIVIAIDS}

The participants reported that they actually do not take into consideration the risk of contracting STIs when they engage themselves in the raping process. This has been found out when they responded to the question "Have you considered the danger of rape (e.g. non condom use, STIs"? Participants showed some apprehension and responded as follows;

\footnotetext{
"During that time when you rape a girl especially the one you want the most things like STIs do not come to mind". "But mhh.... in the porn movies they do not use condoms, how can we be sick?"

"No I never thought about any danger because when you have used drugs, you just do it without carrying condoms and you want an immediate gratification"

"Ndiyaqala ndiyoyika ngoku. Condoms are scarce in the village.... ngoku sithini uma sibatyiwe futhi lama cherry uma sewetipile ngenxa ye alcohol ?"
}

[English translation-I begin be scared. So what must we do when we have erection and these girls have slept because alcohol has impaired their nervous system? ]

These responses reveal that since adolescent males had planned to be experiment pornography, their actions should not be completely attributed to the influence of alcohol. The theory of planned behaviour, an extension of the theory of reasoned action pioneered by Ajzen (1991), affirms that actual behaviour is a function of the intention to act. This theory attempts to explain a number of health behaviours such as smoking and condom use. When adolescent males find sex enjoyable (i.e. affective attitude) and it is approved by significant others in their social realm (e.g. peers), they are more likely to be sexually active and ignore the risks of contracting gonorrhoea, syphilis and/or HIVIAIDS (Ajzen \& Klobas, 2013). Congruent with these findings, Takatshana (2013) found similar results in a quantitative study that $40.9 \%$ of adolescent males indicated to have engaged in unsafe sex while under the influence of alcohol with multiple sexual partnership.

\subsection{Traditional male circumcision}

This theme emerged when the participants informed us that they had undergone traditional male circumcision. They mentioned that it has been quite a long time they practised unsafe sex and had never experienced STIs or opportunistic illnesses. Their responses were as follows:

"Thina soluka. Andicingi ukuba i STIs and HIV/AIDS zingasibamba" [English translation: we have traditionally circumcised. We won't contract HIV/AIDS] "Izifo zingena kumntu onojwabu. Futhi siqhelile ukudibanela amantombi"

[English translation-Sexually transmitted infections penetrate through the foreskin or prepuce. And we are used to swap girls when having sex]

So these answers prove that adolescent males are sexually risk takers and they are stereotyped regarding HIVIAIDS and traditional circumcision. For them being men connotes power and masculinity (Rashe, 2008). In a study conducted by Ntombana (2011) in Black Township, King -Williams Town, Eastern Cape, a girl from Zwelitsha raped on her way back from school and the accused were two young men who had just graduated from their initiation school. From this this findings, sexuality education should be instilled alongside cultural norms and identity to avoid cases of adolescents who will contract HIVIAIDS as a result of lack of knowledge.

\subsection{Statutory rape and imprisonment}

The participants showed ignorance and disregard for legal implications of raping girls when answering the question: Are you aware of the criminal /legal implications of raping girls under the age of 18 (e.g. statutory rape and date rape"? Because they drugged the female counterparts and took advantage of the situation by engaging in sexual intercourse, they saw nothing wrong. Their responses were as follows; 


\begin{abstract}
"How could one be arrested since these girls agreed to be with us and allowed us to spend for them" "These girls did not refuse, as they also enjoyed"

"No. I would say, we are not aware that to have sex with these young girls could lead us into trouble" "I do not know what statutory rape is and what date rape is, but I know that rapists end up in prison"
\end{abstract}

\title{
11. Possible limitations
}

Despite the fact that this study addressed significant questions concerning the impact of pornography on the adolescent males' sexual behaviour in rural areas of the Eastern Cape, there are limitations that ought to be considered. Participants were all isiXhosa speaking, thus language was a shortcoming since questionnaires had to be translated to isiXhosa for them to better understand the content of the question. Furthermore, owing to the geographical location and the practice of traditional male circumcision, it can be argued the sample cannot represent a typical adolescent who sexual coerces their partners. However, the empirical findings correlate with some previous research studies.

\section{Recommendations}

The researchers recommend family, and the community to take part in preventing rape. At family level, a warm and secure environment which inculcates values and morals to adolescence should encourage adolescent males to devote much time to their studies and sports as opposed to a hostile environment where they witness violence and pornography thereby developing antisocial behaviour. Because sexuality education is integrated in the curriculum, it is imperative that children may be taught the dangers of rape (e.g. STI's, imprisonment and unplanned fatherhood) so that the stereotypes about demeaning females maybe corrected.

\section{Acknowledgements}

The authors gratefully acknowledge the Department of Education for granting them permission to allow adolescent males to participate in the study. Lastly, this study would not have been possible without the financial support from the Govan Mbeki Research and Development Centre form the University of Fort Hare.

\section{References}

Ajzen, I. (1991). Theory of planned behavior. Organizational Behavior and HumanDecision Processes, 50, 179-211. doi:10.1016/07495978(91)90020-T.

Ajzen, I., \& Klobas, J. (2013). Fertility intentions: An approach based on the theory of planned behavior. Demographic Research, 29.

Babbie, E (2008). Introduction to social research. (5th edition). Wadsworth Cencage learning: Australia

Bahr, J.S, Hoffmann J.P and Yang, X. (2005). Parental and peer influences on the risk of adolescent drug use. Journal of Primary Prevention. Volume 26 (6), 529-551.

Bale, C. (2010). Raunch or romance? Framing and Interpreting the relationship between sexualized culture and young people's sexual health. Sex Education, 11, 303-313

Best, C., \& Fortenburry, J.D.(2013). Adolescent Sexuality and Sexual Behaviour. In handbook of Adolescent Health Psychology (pp 277291). Springer: New York

Bonino, S; Garano, S; \& Rabaglietti, E. (2006). Use of pornography and self reported engagement in sexual violence among adolescents. European Journal of Developmental Psychology, 3, 265-288.

Brand, M., Laier, C., Pawlikowski, M., Schachtle, U., Schoeler, T., \& Altstottler-Gleish, C, (2011). Watching pornographic pictures on the internet: Role of Sexual Arousal Ratings and psychological Psychiatric Symptoms for Excessively. Cyperpsychology,Behaviour, and Social Networking, 14 (6), 371-376.

Brandy, A., Brian, L., Marget, L., Sharon, S. (2004). The Impact of Religiosity on Adolescent Sexual Behavior. SAGE Publications:

Braun-Courville, D. K., \& Rojas, M. (2009). Exposure to sexually explicit web sites and adolescent sexual attitudes and behaviors. Journal of Adolescent Health, 45(2), 156-162.

Brown, J. D., Keller, S., \& Stern, S. (2009). Sex, sexuality, sexting, and sexed: adolescents and the media. Prevention Researcher, 16(4), $12-16$.

Casey, B. J., \& Jones, R. M. (2010). Neurobiology of the adolescent brain and behaviour: implications for substance use disorders. Journal of the American Academy of Child \& Adolescent Psychiatry, 49(12), 1189-1201.

Chisholm, J. F., \& Day, S. K. (2013). Current trends in cyberbullying. Journal of Social Distress and the Homeless, 22(1), 35-57.

Clive B. (2004) Yizo-Yizo: Citizenship, Commodification and Popular Culture in South Africa. University of Bistol:

Comer, R. J. (2013). Abnormal Psychology. Library of congress: United States of America.

Cowell, A., \& Smith, E. (2009). Streetwise pornography research. Newcastle upon Tyne: Streetwise Young People's Project. 
Creswell, J.W. (2008). Research Design Qualitative: Quantitative \& Mixed methods Approach. (3rd ed). Sage Publications Ltd: United States of America.

de Bruijn, P., Burrie, I., \& van Wel, F. (2006). A risky boundary: Unwanted sexual behavior among youth. Journal of sexual aggression, 12(2), 81-96.

de Vos, A.S., Strydom, H., Fouche, C.B. \& Delport, C.S.L. (2011). Research at grass roots for social sciences and human service professions. (4th ed). Van Schaik Publishers: Pretoria.

Delmonico, D. L., \& Griffin, E. J. (2008). Cybersex and the E-teen: What Marriage and Family Therapists Should Know. Journal of marital and family therapy, 34(4), 431-444.

Döring, N. (2014). Consensual sexting among adolescents: Risk prevention through abstinence education or safer sexting? Cyberpsychology, 8(1).

Eaton, L., Flisher, A. J., \& Aarø, L. E. (2003). Unsafe sexual behaviour in South African youth. Social science \& medicine, 56(1), 149165.

Eberstadt, M., \& Layden, M. A. (2010). The social costs of pornography: A statement of findings and recommendations. Witherspoon Institute, Inc : Princeton, $\mathrm{NJ}$.

Elliot, I.A., \& Beach , A.R. (2009). Understanding online child pornography use: Applying sexual offence theory to internet offenders. Aggression and violent Behaviour, 14, 280-193.

Flood, M. (2009). The Harms of Pornography Exposure Among Children and Young People. Child Abuse Review, 18, 384-400.

Flores, J.K. (2005). Statutory rape known to law enforcement. US Department of Justice

George, E. (2001). Sexual violence in schools. African policy electronic distribution:

Greenberger, E., Chen, C., Beam, M., Whang, S. M., \& Dong, Q. (2000). The perceived social contexts of adolescents' misconduct: A comparative study of youths in three cultures. Journal of Research on Adolescence, 10(3), 365-388.

Henning, E., Van Rensburg, W., \& Smit, B. (2004). Finding your way in qualitative research. Van Schaik Publishers: Pretoria

Holborn, L. \& Eddy, G. (2011).First Steps to healing the South African Family. A research paper by the South African Institute of Race Relations, Johannesburg. South Africa.

Holtzhausen, L. (2012). Thirteen year old boy implicated in gang rape of seventeen year old mentally disabled girl from Soweto-a case of criminal capacity. Article 40, 14(2), 1-5.

Jemmott, J.B., Ngwane,Z., Hewitt,G. A.L.S., Shell, R., \& O'Leary, A.(2007). Theory of planned behavioral prediction of intention to use Condoms among Xhosa adolescents in South Africa.

Jeriphannos, M., Kudakwashe, M., Phinias,T. (2004). Influences of culture on acquaintance rape among college students. Thesis. Zimbabwe University: Harare.

Jewkes, R. (2012). Rape perpetration: a review in Pretoria, Sexual Violence Research Initiative. Medical Research Council : Pretoria.

Jewkes, R., \& Morrell, R. (2012). Sexuality and the limits of agency among South African teenage women: Theorising femininities and their connections to HIV risk practises. Social Science \& Medicine, 74(11), 1729-1737.

Jewkes, R., Sikweyiya, Y., Morrell, R., \& Dunkle, K. (2011). Gender Inequality, masculinity and sexual entitlement in rape perpetration in South Africa: findings of a cross sectional study. University of Witwatersrand: Johannesburg.

Kheswa, J.G., X. Dayi., \& Gqumani, P. (2014). African Adolescent Males and Rape in the Eastern Cape, South Africa: A Need for Sexuality Education. Mediterranean Journal of Social Sciences, Vol 5 (10), 541-550.

Kirby, D. (2001). Emerging Answers: Research findings on programs to reduce teen pregnancy. National Campaign To Prevent Teen Pregnancy, 1776 Massachusetts Avenue, NW,\# 200, Washington, DC 20036.

Kraus, C., \& Li, G. (2006). Pilot alcohol violations reported in U.S. newspapers.

Lawsky, D. (2008). American youth trail in Internet use: survey. Reuters.

Le Roux, E (2010). 'pornography: human right or human rights violation? HTS Theological Studies, 66 (2), 1-8

Leedy, P. D., \& Ormrod, J. E. (2005). Practical research. Columbus, OH: Pearson Merrill Prentice Hall.

Lenhart, A., Purcell, K., Smith, A., \& Zickuhr, K. (2010). Social Media \& Mobile Internet Use among Teens and Young Adults. Millennials. Pew Internet \& American Life Project

Lincoln, Y.S. \& Guba, E.G. (1985). Naturalistic inquiry. Sage: Beverly Hills. USA

Louw, A. E., \& Winter, M. (2011). The use and trends of information and communication technology (ICT) during middle childhood. Journal of Child \& Adolescent Mental Health, 23(1), 29-42.

Louw, D. \& Louw, A. (2007). Child and adolescent development. University of Free State: Bloemfontein.

Malan, M. (2013).Gender Violence: creating a new normal for South Africa's men. Mail \&Gaurdian. Johannesburg.

Maree, K. (2010). First steps in research. Van Schaik Publishers: Pretoria.

Mesch, G. S. (2009). Parental mediation, online activities, and cyber bullying. Cyber Psychology \& Behaviour, 12(4), 387-393.

Noleen- Hoeksema, S. (2008). Abnormal Psychology. Media \& Research Update. (4th edition.). McGram- Hill Higher Education: Boston.

Ntombana, L. (2011). An investigation into the role of Xhosa male initiation in moral regeneration. Doctoral thesis. Nelson Mandela Metropolitan University: Port Elizabeth.

Omar, S. (2012). Children who sexually abuse other children-A South African Perspective. AFRICAN SUN MeDIA.

Owens, E. W., Behun, R. J., Manning, J. C., \& Reid, R. C. (2012). The impact of Internet pornography on adolescents: A review of the research. Sexual Addiction \& Compulsivity, 19(1-2), 99-122.

Pastorino, E., \& Doyle-Portillo, S. (2009). What is Psychology? International Edition. (2nd edition.).Wadsworth Cengage Learning: Belmont. 
Petersen, I., Bhana, A., \& McKay, M. (2005). Sexual violence and youth in South Africa: The need for community-based prevention interventions. Child abuse \& neglect, 29(11), 1233-1248.

Posel, D. (2008). Getting the nation talking about sex: Reflections on the politics and "non-building" in post-apartheid South Africa.

Poulsen, F. O., Busby, D. M., \& Galovan, A. M. (2013). Pornography use: Who uses it and how it is associated with couple outcomes. Journal of sex research, 50(1), 72-83.

Rashe, R.Z. (2008). Family violence in African communities in the Western Cape. A theological-ethical assessment. (DTh dissertation). University of Stellenbosch: Stellenbosch.

Reid, R. C; Carpenter, B.N \& Fong, T. W. (2011). Neuroscience research fails to support claims that excessive pornography consumption causes brain damage. Surgical Neurology International. Retrieved from http://unh.edu/ccrc/pdf/CV194.pdf

Ryckman, R.M. (2008). Theories of Personality. (9th ed.). Thomson Wadsworth: Belmont

Schachter, S; \& Singer, J. (1962). Cognitive, social, and psychological determinants of emotional state. Psychological review, 69, 379399.

Seto, M. C., Hermann, C. A., Kjellgren, C., Priebe, G., Svedin, C. G., \& Långström, N. (2014). Viewing Child Pornography: Prevalence and Correlates in a Representative Community Sample of Young Swedish Men. Archives of sexual behavior, 1-13.

Stevens, R., \& Cloete, M.G.T. (2004). Introduction to Criminology. Oxford University Press: Cape Town

Takatshana, S. (2013).The impact of alcohol on the sexual behavior of adolescent males in Nkonkobe Municipality. (M.Soc.Sc dissertation). University of Fort Hare: Alice

Thsitake, R. S., Pengpid, S., \& Peltzer, K. (2013). Knowledge and experiences of child care workers regarding care and management of children with special needs in Gauteng, South Africa. Journal of Child \& Adolescent Mental Health, 25(2), 131-138.

Unni, J. C (2010). Adolescent attitudes and relevance to family life education programmes. Indian Pediatrics, 47, 176-179

Wolak, J., \& Finkelhor, D. (2013). Are crimes by online predators different from crimes by sex offenders who know youth in-person? Journal of Adolescent Health, 53(6), 736-741.

World Health Organization. (2007). Global strategy for the prevention and control of sexually transmitted infections: 2006-2015: breaking the chain of transmission.

Zenzile, E. (2008). Juvenile delinquency among secondary school pupils in the Mthatha District of Education: A Self-Report Survey (Doctoral dissertation, Department of Criminal Justice, University of Zululand). 